\title{
Smart Electric Solar Car Application System Based on Android
}

\section{Sistem Aplikasi Smart Electric Solar Car Berbasis Android}

\author{
Ahmad Riyadi $\left.{ }^{1 *}\right)$, Haryanto ${ }^{2}$, Koko Joni $^{3}$, Achmad Ubaidillah ${ }^{4}$ \\ \{Corresponding Author: iyanbwean@gmail.com ${ }^{1}$ \}
}

Program Studi Teknik Elektro, Fakultas Teknik, Universitas Trunojoyo Madura

\begin{abstract}
Electronic devices that are increasingly developing make alternatives to human activities every day so that human work can be completed easily. Like smartphones as electronic devices that have dominated electronic devices so that users have the convenience of fulfilling their needs. There have been many electronic devices that can be controlled by simply pressing the remote button without even touching anything but by voice commands. Technology has developed rapidly so that a microcontroller like Arduino can be integrated with other devices, such as an electric car that is equipped with solar panels as a source of electrical energy and controlled via an Android smartphone. In this study, an electric car will be controlled by an application on a smartphone with voice commands, and using bluetooth as a connection between the application system and the electric car system.
\end{abstract}

Keywords - Android smartphone; Application; Electric car; Voice Command

Abstrak. Perangkat elektronik yang semakin berkembang menjadikan alternatif pada aktifitas manusia setiap hari sehingga pekerjaan manusia dapat diselesaikan dengan mudah. Seperti smartphone sebagai perangkat elektronik yang sudah merajai perangkat elektronik sehingga para pengguna mendapatkan kemudahan dalam memenuhi kebutuhannya. Sudah banyak alat elektronik yang bisa dikendalikan dengan hanya menekan tombol remote bahkan tanpa sentuhan apapun melainkan dengan perintah suara. Teknologi yang sudah berkembang dengan pesat sehingga microcontroller seperti arduino dapat diintegrasikan dengan alat lainnya, seperti mobil listrik yang telah dilengkapi panel surya sebagai sumber energi listriknya dan dikontrol melalui smartphone android. Pada penelitian ini mobil listrik akan dikontrol oleh aplikasi pada smartphone dengan perintah suara, dan menggunakan bluetooth sebagai koneksi sistem aplikasi dengan sistem mobil listrik.

Kata Kunci - Aplikasi; Mobil listrik; Perintah Suara; Smartphone Android

\section{Pendahuluan}

Sumber energi yang paling banyak digunakan di dunia adalah energi fosil yang berupa bahan bakar minyak. Indonesia sendiri saat ini masih sangat tergantung pada energi fosil [1]. Hampir 95\% dari kebutuhan energi Indonesia masih disuplai oleh energi fosil. Sekitar 50\% dari energi fosil tersebut adalah minyak bumi dan sisanya adalah gas dan batubara [2]. Energi fosil adalah energi yang tak terbarukan dan akan habis pada beberapa tahun yang akan datang. Diprediksi tidak lebih dari 50 tahun lagi energi fosil di dunia akan habis. Selain karena akan habis, energi fosil juga berdampak negatif terhadap lingkungan [3]. Emisi gas rumah kaca dari pembakaran energi fosil berdampak pada pemanasan global yang menyebabkan perubahan iklim. Energi utama yang dikonsumsi oleh masyarakat Indonesia sebagian besar juga berasal dari energi fosil. Energi fosil tersebut sering kita sebut BBM (Bahan Bakar Minyak) [4].

Krisis energi pada tahun 1970 sampai 1980 menjadikan masyarakat kembali meminati mobil listrik. Pada awal 1990, California Air Resources Board (CARB) mulai menekan para pabrik otomotif untuk mulai memproduksi mobil yang lebih efisien dalam subsidi bahan bakar, memiliki emisi rendah, dan tujuan akhirnya untuk membuat kendaraan dengan nol emisi seperti mobil listrik [5]. Perusahaan Tesla Motors mulai mengembangkan Tesla Roadster pada tahun 2004 kemudian diluncurkan pada tahun 2008 terhadap publik..

Dengan adanya teknologi yang berkembang semakin canggih menjadikan pekerjaan manusia lebih mudah dengan hanya menekan tombol pada smartphone android. Dengan menambahkan sistem aplikasi pada mobil listrik diharapkan mobil listrik juga bisa dikontrol dengan smartphone. Karena beberapa keuntungan yang dimiliki mobil listrik untuk masa depan dengan mengikuti perkembangan teknologi canggih saat ini, menjadikan mobil listrik sebagai kendaraan alternatif yang mudah perawatannya dan regeneratif.

\section{METODE}

Aplikasi merupakan perangkat lunak yang digunakan sebagai kontrol dari mobil listrik. Mobil listrik akan dikontrol melalui aplikasi pada smartphone dengan mengirimkan perintah suara. Untuk mengenali perintah suara 
yang telah dikirimkan dengan menggunakan Speech Recognition yang nantinya akan diterjemahkan menjadi suatu yang dimengerti oleh sistem mobil listrik.

Metode Speech Recognition juga merupakan sistem yang digunakan untuk mengenali perintah kata dari suara manusia dan kemudian diterjemahkan menjadi suatu data yang dimengerti oleh komputer. Keuntungan dari sistem ini adalah pada kecepatan dan kemudahan dalam penggunaannya. Hasil akhirnya jika tombol yang pada aplikasi android ditekan maka akan merekam suara lalu suara akan dikirim ke arduino lewat Bluetooth dan jika perintah suara sesuai maka mobil robot akan berjalan.

\section{A. Arduino nano}

Arduino Nano adalah salah satu papan pengembangan mikrokontoler yang berukuran kecil, lengkap dan mendukung penggunaan breadboard. Arduino Nano diciptakan dengan basis mikrokontroler ATmega328 (untuk Arduino Nano versi 3.x) atau ATmega 168 (untuk Arduino versi 2.x). Arduino Nano kurang lebih memiliki fungsi yang sama dengan Arduino Duemilanove, tetapi dalam paket yang berbeda. Arduino Nano tidak menyertakan colokan DC berjenis Barrel Jack, dan dihubungkan ke komputer menggunakan port USB Mini-B. Arduino Nano dirancang dan diproduksi oleh perusahaan Gravitech [6].

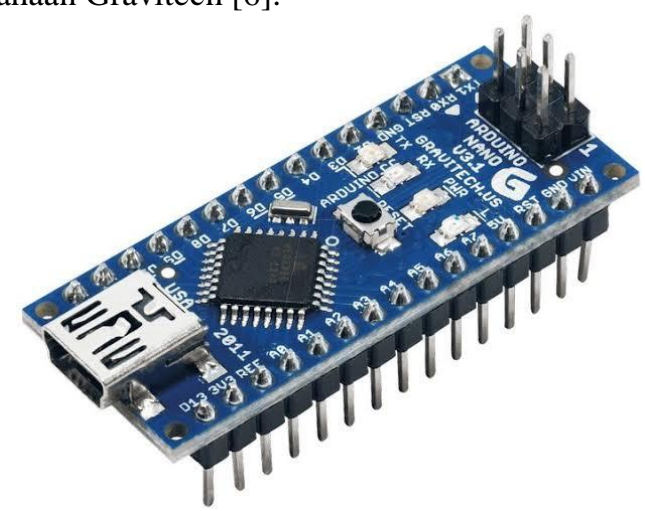

Gambar 1. Arduino Nano

\section{B. Bluetooth HC-05}

Bluetooth HC-05 merupakan sebuah modul wireless bluetooth dengan komunikasi serial SPP(Serial Port Protocol) yang beroperasi pada frekuensi 2,4 GHz dimana kita bisa berkomunikasi antar perangkat. Module ini bisa digunakan sebagai slave (penerima) maupun sebagai master (pengirim). Disamping itu bluetooth HC-05 juga mempunyai 2 mode konfigurasi yang pertama adalah AT-Mode, dan Communication Mode [7].

AT-Mode merupakan mode untuk konfigurasi pengaturan module HC-05. Disini kita bisa mengatur berbagai pengaturan, contohnya mengganti password dan nama Bluetooth [8]. Sedangkan Communication Mode merupakan mode pada saat kita akan berkomunikasi dengan perangkat lain atau dapat dikatakan sebagai mode running [9].

\section{HC-05}

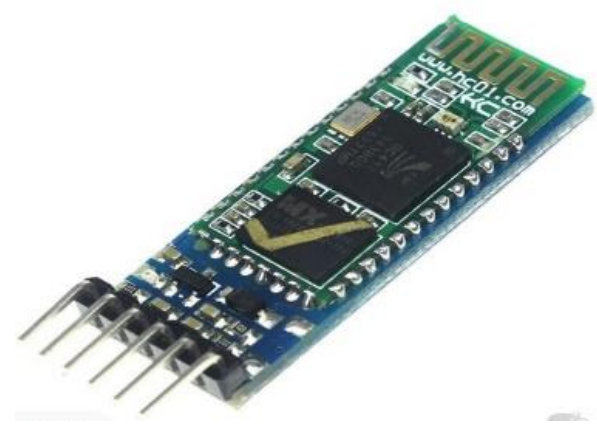

Gambar 2. Bluetooth HC-05

\section{Blok diagram sistem}

Pada sistem aplikasi ini terdapat beberapa tahapan agar sesuai dengan yang diharapkan, berikut adalah bentuk blok diagram. 


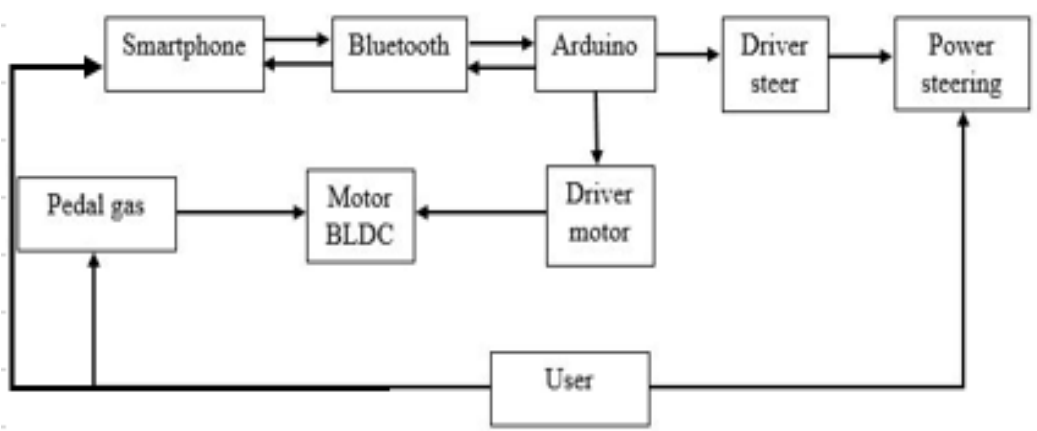

Gambar 3. Blok Diagram

Pada blok diagram diawali dari user yang bisa memilih mode auto atau mode manual. Jika memilih mode auto maka user akan mengaktifkan aplikasi dengan mengirimkan perintah suara melalui aplikasi android dan akan dikirim pada arduino melalui koneksi bluetooth, selanjutnya ardino akan mengirimkan perintah pada sistem mobil listrik. Jika user menggunakan mode manual maka user hanya menginjak pedal gas yang ada pada mobil listrik dan mengendalikan dengan power steering.

\section{Konsep sistem}

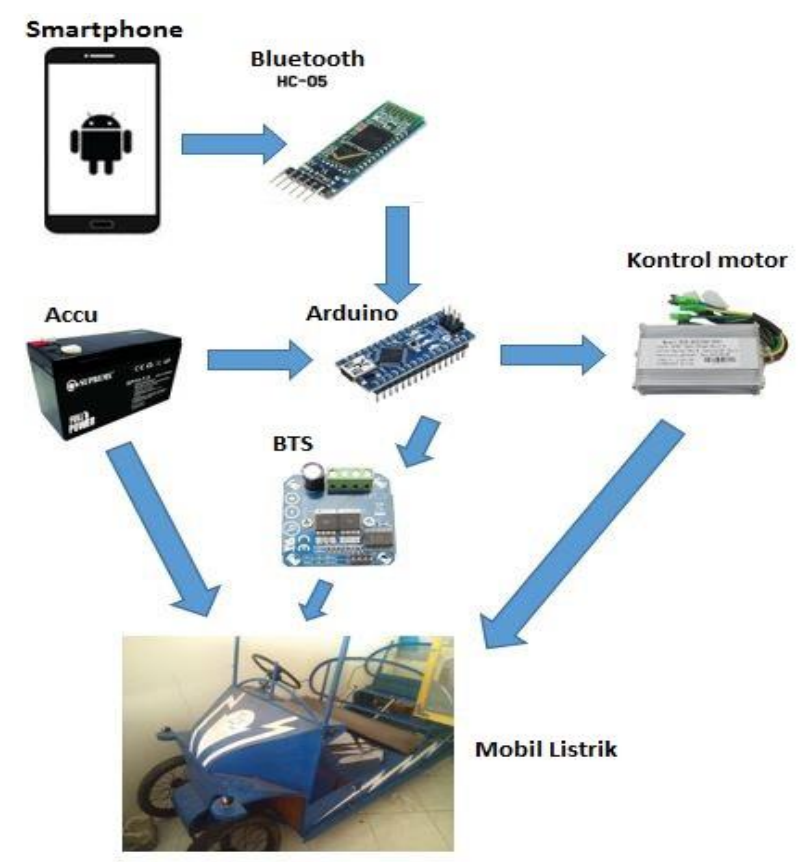

Gambar 3. Konsep Sistem

Konsep sistem merupakan aplikasi dimana aplikasi sebagai kontrol untuk mengendalikan mobil listrik. Dengan mengirimkan perintah suara pada aplikasi android kemudian akan dikirimkan pada arduino melalui bluetooth yang sudah terkoneksi dengan sistem mobil, maka arduino akan mengirim perintah pada driver sesuai perintah yang dilakukan user. Sedangkan accumulator berfungsi sebagai suplai listrik pada seluruh komponen mobil listrik. 


\section{E. Alur sistem aplikasi}

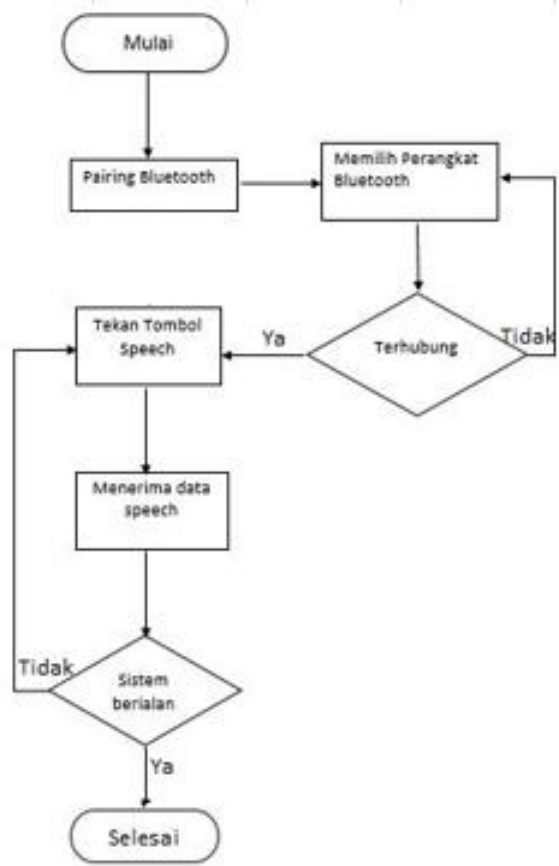

Gambar 5. Flowchart Sistem

Pada flowchart sistem yang diawali dengan proses pairing bluetooth, selanjutnya user menekan tombol pada aplikasi dan melakukan perintah suara maka datayang dikirimkan akan diproses oleh sistem control mobil, jika sudah sesuai proses akan selesai dan mobil akan berjalan. Jika tidak sesuai user diminta untuk mengulangi lagi.

\section{Hasil dan Pembahasan}

Pada sistem aplikasi ini sangatlah mudah dan sederhana, kita hanya mengirimkan perintah suara pada aplikasi kemudian akan diproses oleh sistem kendali mobil listrik.

\section{A. Pengujian bluetooth}

Pengujian ini dilakukan untuk mengetahui apakah Bluetooth Slave dapat menerima informasi secara serial yang dikirim oleh Bluetooth Master, sejauh mana Bluetooth Master dapat mengirim data pada Bluetooth Slave yang akan

Tabel 1. Hasil Pengujian Bluetooth

\begin{tabular}{cccc} 
No & Jarak $(\mathrm{m})$ & Data terkirim & $\%$ Error \\
\hline 1 & 1 & Ya & $0 \%$ \\
\hline 2 & 3 & Ya & $0 \%$ \\
\hline 3 & 5 & Ya & $0 \%$ \\
\hline 4 & 8 & Ya & $0 \%$ \\
\hline 5 & 10 & Tidak & $50 \%$
\end{tabular}

Pada tabel diatas dilakukan beberapa percobaan dengan jarak yang berbeda. Diantara percobaan tersebut uji coba bluetooth bisa terhubung dengan aplikasi dan mengirimkan perintah sesuai pada kontrol mobil. Pada percobaan kelima dengan jarak $10 \mathrm{~m}$ ada error pada koneksi bluetooth dengan aplikasi dikarenakan jarak yang terlalu jauh sehingga data tidak dapat terkirim. 


\section{B. Pengujian aplikasi}

Pengujian ini dilakukan untuk mengetahui apakah data yang dikirim dari smartphone terhadap sistem kendali mobil sudah benar atau tidak. Pengujian dilakukan dengan mengirimkan beberapa perintah seperti maju,stop. (berhenti), mundur, kanan, kiri, dan lurus.

Tabel 2. Pengujian Aplikasi Android

\begin{tabular}{cccc}
$\begin{array}{c}\text { Perintah } \\
\text { smartphone }\end{array}$ & $\begin{array}{c}\text { Respon } \\
\text { mobil }\end{array}$ & $\begin{array}{c}\text { Hasil } \\
\text { pengujian }\end{array}$ & $\begin{array}{c}\text { Delay } \\
\text { (detik) }\end{array}$ \\
\hline Maju & Maju & Berhasil & 3 \\
\hline Stop & Stop & Berhasil & 5 \\
\hline Mundur & Mundur & Berhasil & 3 \\
\hline Kanan & Kanan & Berhasil & 4 \\
\hline Kiri & Kiri & Berhasil & 4 \\
\hline Lurus & Lurus & Berhasil & 4
\end{tabular}

Dari tabel diatas didapatkan hasil uji coba sistem aplikasi pada mobil listrik. Pada pengujian dilakukan dengan mengambil data sebanyak 3 kali pada setiap sampel dan di dapatkan hasil respon dari mobil listrik yang berbedabeda pada setiap sampel pengujiannya. Pada sampel pengujian stop didapat delay sebesar 5 detik dikarenakan pada saat pengujian ini mobil sedang melaju, sama halnya pada saat sampel pengujian belok kanan, belok kiri, dan lurus. Pada saat pengujian maju dan mundur didapat delay sebesar 3 detik yaitu dikarenakan pada pengujian ini mobil sedang dalam keadaan diam atau tidak berjalan.

\section{Pengujian perintah suara maju pada aplikasi}

Pengujian ini dilakukan untuk mengetahui hasil perintah suara pada aplikasi dengan perintah yang dikirimkan pada mobil listrik, dan untuk mengetahui hasil kecepatan mobil listrik pada saat berjalan.

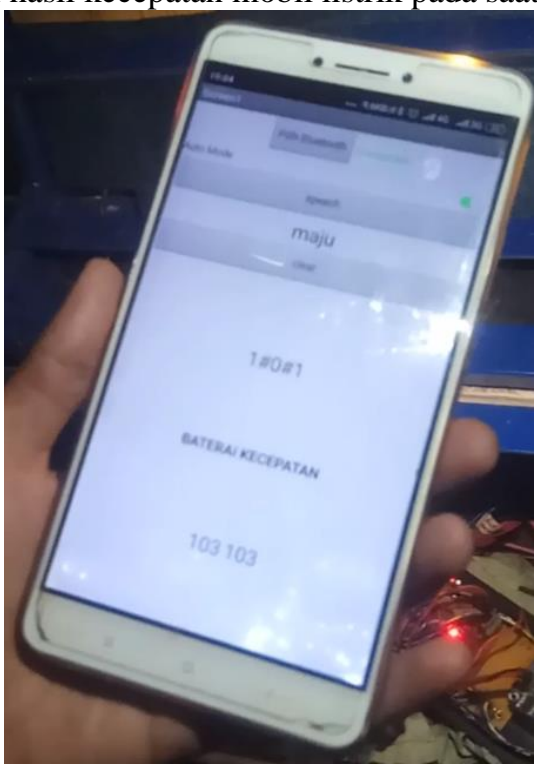

Gambar 6. Hasil Pengujian Perintah Suara Maju Dari Aplikasi

Pada gambar 6 adalah hasil dari pengujian perintah suara maju yang diperoleh data 1\#0\#1 dimana 1 paling depan menunjukkan bahwa perintah maju telah diterima oleh kontrol sistem pada mobil, angka 0 menunjukkan bahwa tidak ada perintah untuk belok kanan dan kiri serta lurus, sedangkan angka 1 paling belakang menunjukkan bahwa user sedang mengaktifkan auto mode agar perintah dari aplikasi dapat diterima oleh arduino dan diteruskan pada mobil. 


\section{Pengujian perintah suara mundur pada aplikasi}

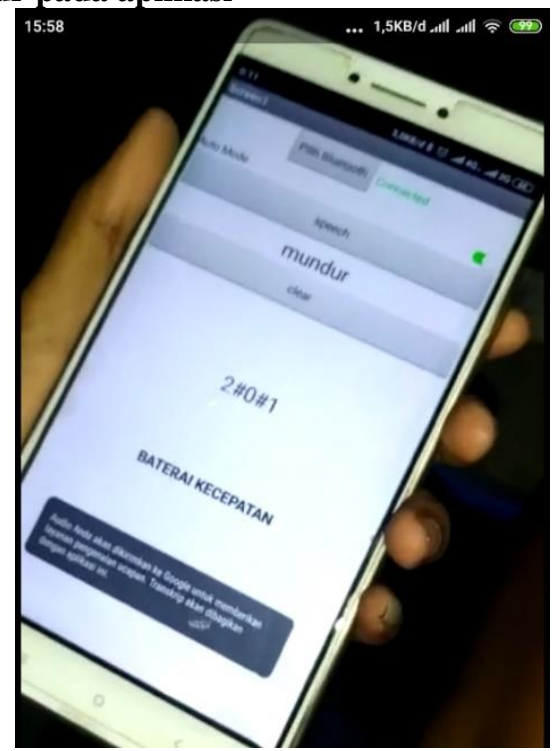

Gambar 7. Hasil Pengujian Perintah Suara Mundur Dari Aplikasi

Pada gambar 7 adalah hasil dari pengujian perintah suara maju yang diperoleh data 2\#0\#1, untuk melakukan perintah mundur sebaiknya mobil dalam keadaan berhenti agar tidak terjadi kerusakan pada gear persneling. Pada saat kondisi mundur sistem mobil listrik akan mengaktifkan persneling mundur dan roda akan bergerak ke arah belakang.

\section{E. Pengujian perintah suara stop pada aplikasi}

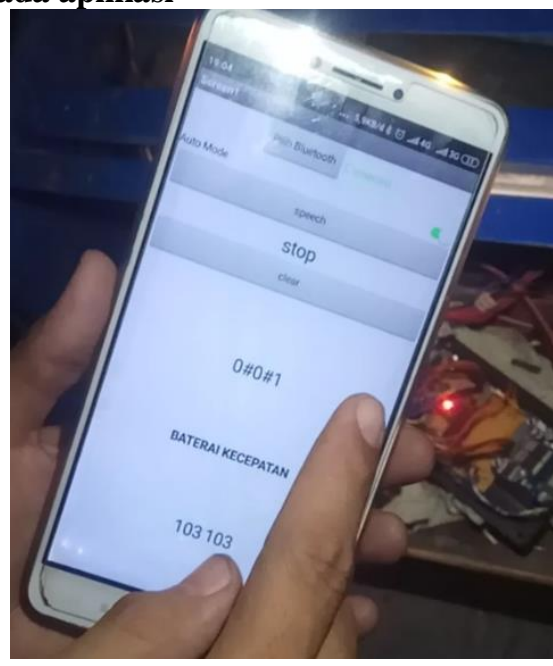

Gambar 8. Hasil Pengujian Perintah Suara Stop Dari Aplikasi

Pada gambar 8 adalah hasil perintah suara stop atau berhenti. Maka didapatkan data 0\#0\#1 yaitu ketika perintah berhenti maka kondisinya akan $0 \# 0$ atau kondisi mobil sedang tidak berjalan, dan 1 adalah auto mode sedang diaktifkan oleh user. 
Procedia of Engineering and Life Science Vol.1 No. 1 March 2021

Seminar Nasional \& Call for Paper Fakultas Sains dan Teknologi (SENASAINS $1^{\text {st }}$ )

Universitas Muhammadiyah Sidoarjo

\section{F. Pengujian perintah suara kanan pada aplikasi

Screen1
Auto Mode Bluetooth connected
speech
kanan
clear

0\#2\#1

BATERAI KECEPATAN

Gambar 9. Hasil Pengujian Perintah Suara Kanan Dari Aplikasi

Pada gambar 9 adalah hasil pengujian ketika belok kanan, saat melakukan belok kanan bisa dilakukan ketika mobil sedang berjalan, ketika melakukan perintah untuk belok kanan maka diperoleh data 0\#2\#1 dan power steering akan mendapat perintah dari arduino dengan berputar kearah kanan sesuai dengan program yang telah ditentukan.

\section{G. Pengujian perintah suara kiri pada aplikasi}

Pilih Bluetooth connected

\begin{tabular}{l} 
Auto Mode \\
speech \\
\hline kiri \\
clear \\
\hline
\end{tabular}

$0 \# 1 \# 1$

BATERAI KECEPATAN

Gambar 10. Hasil Pengujian Perintah Suara Kiri Dari Aplikasi

Pada gambar 10 adalah hasil pengujian ketika belok kiri, saat melakukan belok kiri bisa dilakukan ketika mobil sedang berjalan, ketika melakukan perintah untuk belok kiri maka diperoleh data 0\#1\#1 dan power steering akan mendapat perintah dari arduino dengan berputar kearah kiri sesuai dengan program yang telah ditentukan. 


\section{H. Pengujian perintah suara lurus pada aplikasi}

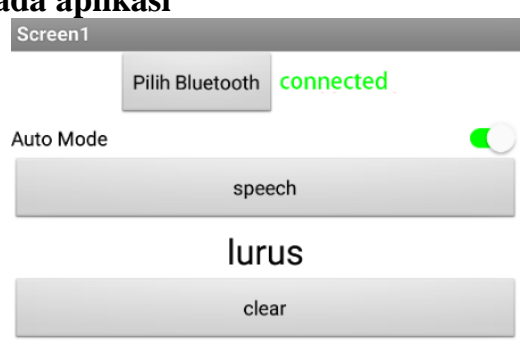

0\#3\#1

BATERAI KECEPATAN

Gambar 11. Hasil Pengujian Perintah Suara Lurus Dari Aplikasi

Pada gambar 11 adalah hasil pengujian ketika perintah lurus yang diperoleh data 0\#3\#1, perintah lurus bisa dilakukan ketika mobil belok kiri atau belok kanan yang bertujuan agar laju mobil kembali pada jalurnya setelah melakukan belok kiri atau kanan. Pada kondisi ini power steering akan mendapat perintah ke titik tengah steering pada mobil.

\section{KESIMPULAN}

Pada saat menggunakan mode manual dapat diatur kecepatan dan kendali dengan cepat, dan kecepatan pada saat mode manual bisa mencapai kecepatan maksimal hingga $35 \mathrm{~km} / \mathrm{j}$. Pada saat menggunakan auto mode yaitu menggunakan kedali dari aplikasi. Menggunakan perintah suara untuk mengendalikan mobil dengan kecepatan 35 $\mathrm{km} / \mathrm{j}$, dan pada penggunaan auto mode ini ada delay ketika melakukan perubahan pergerakan mobil dari lurus ke kiri, lurus ke stop, dan seterusnya, sehingga dapat diperoleh delay 3 sampai 5 detik dari perintah yang dikirim.

\section{UCAPAN TERIMA KASIH}

Terimakasih saya ucapkan kepada Allah SWT yang telah memberikan nikmat sehat kepada hambanya sehingga bisa menyelesaikan paper ini. Tidak lupa saya haturkan shalawat serta salam kepada junjungan nabi besar Muhammad SAW yang telah membawa dari alam yang gelap menuju alam yang terang menderang ini. Terimakasih juga saya sampaikan pada segenap pihak yang telah membantu dalam pembuatan paper ini, dan kedua orang tua saya ucapkan banyak terimakasih karna berkat doa beliau saya bisa melalui dan menyelesaikan study saya.

\section{REFERENSI}

[1] W.-K. Chen, Linear Networks and Systems. Belmont, CA: Wadsworth, 1993, pp. 123-135.

[2] N. Chayati, A. Haryoko, and A. Wijayanti, "Perancangan Mobil Robot Dengan Pengendali Suara," no. September, 2018.

[3] M. I. Adi, "Rancangan Sistem Start Engine," pp. 1-12, 2017.

[4] Sumardi, " Perancangan Sistem Starter Sepeda Motor” Pros. Semin. Ilmu Komput. dan Teknol. Inf., vol. 2, no. $1,2017$.

[5] I. P. A. Cendana, A. Agung, K. Agung, C. Wiranatha, and K. S. Wibawa, "Aplikasi Pengontrol Robot Mobil Menggunakan Suara Berbasis Android," vol. 5, no. 2, pp. 1-10, 2017.

[6] P. S. Sahu, A. Kumar, and C. M. Bajpai, "Design Analysis and Theoretical Study of Solar Energy Conversion in an Electric Car," pp. 1146-1150, 2016.

[7] S. Gaikwad, S. Sanas, P. Kalwankar, and D. Harale, "Virtual Smart Car,” pp. 2998-3002, 2017.

[8] A. Widiyanto, "Rancang Bangun Mobil Remote Control Android dengan Arduino Prototype of Android RC Car by Arduino," no. March, 2017.

[9] A. Fadilah, "Rancang Bangun Mobil Remote Conrol dengan Smartphone Android Menggunakan Sensor US016 Berbasis Arduino Uno," 2017.

[10] I. P. Prakoso, “Voice Controlled Home Automation System ” 2018. 
Procedia of Engineering and Life Science Vol.1 No. 1 March 2021

Seminar Nasional \& Call for Paper Fakultas Sains dan Teknologi (SENASAINS $1^{\text {st }}$ )

Universitas Muhammadiyah Sidoarjo

[11] M. R. Antoni and I. Sulistiyowati, “ Sistem Kemudi Menggunakan Smartphone Android Pada Prototype Mobil Listrik Umsida Berbasis" pp. 1-8. 